\title{
Recent Insights into Treatment of Non-Alcoholic Steatohepatitis
}

\author{
Audrey Coilly ${ }^{1,2,3,4}$ and Franck Chiappini ${ }^{1,2,3 *}$ \\ ${ }^{1}$ Inserm U1193, Villejuif, F-94800, France \\ ${ }^{2}$ Univ Paris-Sud, UMR-S1193, Villejuif, F-94800, France \\ ${ }^{3}$ DHU Hepatinov, Villejuif, F-94800, France \\ ${ }^{4}$ AP-HP Hôpital Paul-Brousse, Centre Hépato-Biliaire, Villejuif, F-94800, France
}

Received: March 04, 2016; Accepted: March 28, 2016; Published: March 31, 2016

*Corresponding author: Franck Chiappini, Inserm U1193, Hôpital Paul Brousse, Centre Hépatobiliaire, 12 avenue Paul Vaillant Couturier, F-94800,

Villejuif, France, Tel : +33 (0)1 455960 84; Fax: +33 (0)1 495990 26; E-mail: franck.chiappini@inserm.fr

\begin{abstract}
Non-Alcoholic Fatty Liver Disease (NAFLD) represents a major public health issue worldwide. The main characteristic of NAFLD is the accumulation of lipids in hepatocytes to form lipid droplets. The spectrum of NAFLD ranges from non-alcoholic fatty liver (i.e., steatosis) to Non-Alcoholic Steatohepatitis (NASH), a progressive condition increasing in Western Countries and leading to cirrhosis, liver failure and hepatocellular carcinoma. The prevention of NAFLD requires strategies for careful management and monitoring of patients with obesity, diabetes and other components of metabolic syndrome. There is no currently approved treatment that can reverse NASH once it is established. There is no evidence that pioglitazone or vitamin $\mathrm{E}$ can improve fibrosis. Life-style changes and bariatric surgery may improve hepatic histology in some patients with NASH. Currently, a few new drugs targeting pathways that have recently been implicated in the development of NAFLD are under development. Therefore, treatment of NASH should be approached as a complex therapy that would take into account etiology of the disease and patient's history. This review summarizes recent insights into the treatment of NASH.
\end{abstract}

Keywords: NAFLD; NASH; Metabolic syndrome; Obeticholic acid; Treatment

\section{Introduction}

For the last two decades, Non-Alcoholic Fatty Liver Disease (NAFLD) and especially Non-Alcoholic Steatohepatitis (NASH) have been the main cause of chronic liver disease in the Western Countries as well as in Middle East, Asia, Africa and South America [1-4]. The increasing prevalence of NAFLD and NASH in developing countries correlates with changes in lifestyle such as consumption of fast-food, soft soda sugar-sweetened beverages and sedentary lifestyle, leading to the increased prevalence of obesity. NAFLD is usually associated with obesity, insulin resistance and type 2 diabetes, dyslipidemia and metabolic syndrome, which affect both adult and pediatric populations [1-11]. NAFLD also increases the risk for development of Cardiovascular Disease (CVD) independently to other risk factors $[12,13]$, making NAFLD not only a liver disease but also a "systemic disease".

NAFLD is a condition ranging from simple Non-Alcoholic Fatty Liver (NAFL) to NASH, steatofibrosis and cryptogenic cirrhosis. The main characteristic of these lesions is fat accumulation in the form of diacylglycerols and triglycerides contained in hepatic lipid droplets. NAFL is usually considered as benign and reversible whereas NASH may progress to liver failure, cirrhosis and hepatocellular carcinoma $[2,6,7,9,14]$.

The diagnosis of NAFLD is made by histology that still remains the gold standard. Diagnosis of NASH is a little more complicated because it encompasses hepatic steatosis, ballooning of hepatocytes, Mallory's body and inflammation, which may or may not be associated fibrosis. For the past years, some groups worked on better defining NASH by developing different scores such as the NASH Activity Score (NAS) or the Steatosis, Activity and Fibrosis (SAF) score [15-18].

In attempts to better understand the onset and progression of NASH and find therapeutic targets for its treatment, a number of different mechanisms have been described [14,19-21]. Mitochondrial dysfunction (e.g. decreased $\beta$-oxidation and increased oxidative stress), impaired lipid metabolism (e.g. nuclear receptors and transcription factors implicated in de novo lipogenesis) and excretion (e.g. bile acids synthesis and lipoproteins homeostasis) have been raised to play a role $[11,14,19$ 25], but so far, no mechanism specifically linked to NAFLD, and especially $\mathrm{NASH}$, has been pinpointed to explain accumulation of the lipids in the liver and predict the progression of the disease.

Therefore, because prevalence and severity of NASH associated with its hepatic and systemic complications are dramatically increasing worldwide, there is an urgent need to find remedies to decrease or even stop its progression. The first line of intervention is the lifestyle changes. But, academic and pharmacological laboratories are also focused on developing drug therapies. In this review, we will focus on the recent advances in NASH treatments, the failures and the hopes.

\section{Life style modifications}

Diet: Lipid overload in the liver is mainly due to high-caloric diets also known as Western Country diets. The high content of lipids such as cholesterol saturated and n-6 unsaturated fatty acids (i.e., decrease in $\mathrm{n}-3$ to $\mathrm{n}-6$ polyunsaturated fatty acids ratio) combined with high sugar content (mainly fructose) has been implicated in the occurrence and progression of NASH [26]. The obvious goal would be to modify the diet by decreasing cholesterol, Saturated Fatty Acid (SFA) and fructose intake, and increase n-3 Polyunsaturated Fatty Acid (PUFA) intake. The whole caloric intake has to be decreased by $25 \%$ in calories from the normal diet 
based on patient's sex and age according to the World Gastroenterology Organization Global Guidelines [27-30].

Small observational studies showed that a weight loss exceeding $7 \%$ of body weight over 1 year improves histology in patients with biopsyproven NASH [31,32]. More durable weight loss can be achieved in patients with NAFLD by combining diet and exercise for a period longer than one year [33]. It is now recommended that hypocaloric diet should provide 1000-1200 calories per day for women and 1200-1500 calories per day for men with a goal to achieve a weight loss of 0.5-1.0 kg per week based on published guidelines [34].

It has been shown that moderately calorie-restricted diet with changes in macronutrient composition leads to better results compared to a very-low-caloric diet with $5 \%$ to $10 \%$ weight loss as the goal [35]. Furthermore, low-fat diet associated with weight loss program improves body weight, Body Mass Index (BMI), fatty liver, insulin sensitivity and plasma triglycerides [36]. Importantly, heavy alcohol consumption should be avoided in NAFLD patients [37].

Mediterranean diet due to preparation with olive oil, rich in n-3 PUFA, might be of additional help to modify hepatic lipid content and decrease cardiovascular risks [38]. Recently, a randomized controlled trial named Mediterranean Dietary Intervention for Adults with Non Alcoholic Fatty Liver Disease (MEDINA) enrolling 94 patients with NAFLD associated with insulin resistance and receiving either Mediterranean diet or lowcaloric diet during 3 months, showed that Mediterranean diet can result in significant benefits in liver fat and Insulin Resistance (IR), independent of weight loss. These changes are sustained at 12 months. However, liver status was only assessed using magnetic resonance spectroscopy. Hence, this study failed to explore further NAFLD progression [39]. Another study directly assessed effects of Mediterranean diet on liver histology and showed that Mediterranean diet was associated with lower probability of development of high grade of hepatic steatosis and NASH $[40,41]$.

Other studies showed that diets enriched in vegetable oils such as canola, olive pomace and olive oils might improve the grade of hepatic steatosis and insulin sensitivity, especially the combination of olive and canola oils [42]. Indeed, the impact of n-3 PUFA has been investigated in the randomized WELCOME trial and showed that high dose of $n-3$ PUFA (docosahexaenoic + eicosapentaenoic, Omacor $^{\circledR}$ ) did not improve microvascular function but was associated with a decrease in hepatic fat content and improvement in NAFLD severity [43-45].

Other studies have been conducted to test different nutrients enriched in Monounsaturated Fatty Acids (MUFA) and n-3 PUFA such as oily fish/fish oil, nuts and avocado and showed improvement in liver fat and steatosis grading, liver function and insulin sensitivity [46-49]. Some recommendations have been made about the optimal consumption of each nutrient (e.g. avocado, nuts, and olive oil) and the amount per day [48].

Some groups have also studied effects of tea, coffee and caffeine consumption on hepatic steatosis, NASH and fibrosis and showed that there was a negative correlation between caffeine consumption and hepatic fibrosis in overweight or obese patients with NASH [50-52]. In addition, coffee may reduce cardiovascular risk factors by favorably affecting inflammation, insulin sensitivity and decreasing hypertension $[53,54]$. Thus, caffeine and its derivatives might have a potential to slow down fibrogenesis during NASH progression but further investigation has to be done to assess their effects on NASH development.

In conclusion, the optimal diet for NAFLD patients is still undetermined. However, patients with NAFLD may benefit from a moderate- to low-carbohydrate ( $40 \%-45 \%$ of total calories) diet, coupled with high MUFA, high n-3 PUFA, low SFA, and low-cholesterol diet.
Physical activity: Associated with the unhealthy diet, sedentary lifestyle contributes to the occurrence of obesity and NAFLD. Changes in lifestyle by increasing physical activity have been shown to improve triglyceride turnover and liver fat accumulation leading to increased hepatic insulin sensitivity and whole lipid oxidation in the body and decreased hepatic free fatty acids uptake independently of weight-loss $[26,30]$. But in both cases, the crucial issue is the motivation. Indeed, the first significant weight-loss improvement might appear after 6 months of training, which may discourage the patients. Therefore, cognitivebehavioral therapy is needed $[41,55,56]$. A systematic review of data from various randomized controlled trials showed that exercise reduced hepatic fat content [57]. The European guidelines suggest at least 150 min per week of moderate-intensity physical activity and at least 75 min per week of vigorous-intensity physical activity, with additional muscle strengthening exercise twice a week [58].

Surgery: Based on the idea that NAFLD/NASH progresses due to the excessive food intake and loss of satiety feeling (e.g. leptin resistance), bariatric surgery may improve NAFLD by reducing food intake [59]. This therapeutic approach is recommended for patients with morbid obesity $\left(>40 \mathrm{~kg} / \mathrm{m}^{2}\right)$ or severe obesity $\left(>35 \mathrm{~kg} / \mathrm{m}^{2}\right)$ associated with complications $[60,61]$. This surgery is offered to the patients that were not able to lose weight after a period of non-surgical treatment $[60,61]$. Several techniques have been reported including sleeve gastrectomy, gastric band and Roux-en-Y gastric bypass. Currently, mini-invasive procedures are favored such as laparoscopic approach [62]. Bariatric surgery has been shown to improve insulin sensitivity, dyslipidemia, systemic hypertension, decrease CVD risks and improve the histological and biochemical parameters of NAFL and NASH [63]. Bariatric surgery is also associated with the most rapid, effective and sustained weight loss $[64,65]$. A recent study showed that bariatric surgery-induced the disappearance of NASH from nearly $85 \%$ of 109 morbidly obese patients [66]. However, recently Goossens et al. showed that obese patients with NASH undergoing bariatric surgery had an increased risk of death compared to obese patients without NASH before surgery. This study emphasizes the importance of the systemic perioperative liver biopsy in obese patients undergoing bariatric surgery as a diagnostic and prognostic assessment of the death risk [67], and also suggests that NASH should be managed, in addition to changes in lifestyle, with drug therapy to decrease the death risk for these patients. At the same time another study has found no correlation between NASH and death after bariatric surgery, so the exact relationship between the two, and potential risk factors are still not clear [68].

\section{Drug therapy}

Because in addition to obesity NASH progression is associated with IR/type 2 diabetes and dyslipidemia, the goal for drug therapy is to improve general conditions by increasing the whole body insulin sensitivity, decreasing lipid absorption, hepatic de novo lipid synthesis and promoting lipid oxidation in skeletal muscle and liver. In this chapter, we will focus on the recent advances in drug therapies of NASH.

Insulin sensitizers: The first idea to treat NASH was to use insulin sensitizers metformin and thiazolidinediones (e.g. pioglitazone, rosiglitazone), which are used extensively to treat IR/type 2 diabetes. Results of the studies of potential effects of metformin on the development of NASH are contradictory. Recently, a meta-analysis showed no benefit of metformin in improving serum aminotransferases or liver histology among NAFLD patients [69]. Thiazolidinediones (TZDs) are selective peroxisome proliferator-activated receptor-gamma agonists. Pioglitazone demonstrated the benefit with histological improvements in NASH patients such as hepatic steatosis, lobular inflammation and ballooning degeneration $[70,71]$. Furthermore, two recent meta-analyses confirmed the histological improvement of NASH in patients treated with pioglitazone [72,73]. In addition, pioglitazone demonstrated mortality 
reduction related to CVD. However, pioglitazone has received black box warning by the Food and Drug Administration due to reports of congestive heart failure. Previously, rosiglitazone has been prohibited in Europe and highly restricted in USA [74-76]. Despite their effects on reducing hepatic gluconeogenesis, intestinal lipid absorption, lipogenesis, lowering serum lipid concentration, improved liver enzymes and increasing global insulin sensitivity, these molecules failed assessments for long-term benefit as they are associated with weight gain, edema, heart failure, risk of CVD and cancer (e.g. bladder cancer) [74-76]

Antioxidants: Because NASH development and progression are associated with oxidative stress, another treatment line is the use of antioxidants. Currently, the most commonly used antioxidant is vitamin E supplementation given at 800 IU per day. It improves inflammation and fibrosis induced by suppression of lipid peroxidation and oxidative stress [77-79]. Several studies suggest that vitamin E improves liver enzymes, hepatic steatosis, and liver injury in NASH patients but robust data including prospective evaluation are currently lacking. Furthermore, deleterious effects and an increase in mortality rate have been suggested in a long-term exposure [80]. Further studies are required to clarify the beneficial role of vitamin E monotherapy in NASH patients.

Despite these effects, several studies have evaluated vitamin E. One important study compared effects of vitamin $\mathrm{E}$ and insulin sensitizers. 247 biopsy-proven NASH patients without diabetes were randomized to receive pioglitazone $30 \mathrm{mg}$, vitamin E $800 \mathrm{IU}$, or placebo for 96 weeks [79]. Vitamin E was superior to placebo with a significantly higher rate of improvement in NASH ( $43 \%$ vs. $19 \%, p=0.001$ ) whereas pioglitazone was not but showed significant benefits in some of the secondary outcomes (decrease in aminotransferase, hepatic steatosis and lobular inflammation).

Pentoxifylline is another antioxidant that has shown benefit through decreasing oxidative stress. In a randomized trial enrolling 55 biopsy-proven NASH patients, it improved histological features of NASH compared to placebo [81]. This result has been confirmed in a recent meta-analysis [82]. Although these results are encouraging, their validation in a large cohort with a longer follow-up is mandatory.

Cholesterol-lowering drugs: Hepatic cholesterol overload due to increasing in hepatic cholesterol synthesis and in intestinal cholesterol absorption participate strongly in the development and progression of NASH [11,12]. A therapeutic strategy is to antagonize both de novo hepatic cholesterol synthesis and/or cholesterol absorption by the gut.

Statins inhibit cholesterol synthesis by targeting the Hydroxy-MethylGlutaryl-Coenzyme A (HMG-CoA) reductase. Therefore, randomized controlled trials have been conducted in patients with NAFLD. Although statins decreased lipid levels, simvastatin did not induce significant improvement in serum aminotransferase levels, hepatic steatosis, necroinflammatory activity, or stage of fibrosis in NASH patients when liver biopsies were conducted [83].

Recently, a preliminary report from 6 patients showed that rosuvastatin could improve NASH within a year of treatment in patients with dyslipidemia [84]. The next step of this study will be to do randomize control trial in a larger cohort of NAFLD/NASH patients with more than a year of follow-up to assess if these effects on NASH improvement are transient and to assess the side effects of the statins (statin-associated muscle symptoms) that may lead to discontinuation of treatment [85].

Statins combination therapy with ezetimibe, an inhibitor of intestinal cholesterol absorption, has been used to decrease the dose of statin and led to a significant decrease in hepatic cholesterol and plasma LDL level. However, the effect of ezetimibe alone or combined with diet is still controversial in terms of improvement of NASH [86-89]. Thus, the new randomized-control study in a larger cohort of patients using ezetimibe alone or combined with diet and/or statins needs to be conducted to

\section{assess the beneficial effect on NASH features.}

FXR agonists: Farnesoid X Receptor (FXR) is a nuclear receptor implicated in the regulation of different genes involved mainly in glucose, bile acid and lipid metabolism. Because the main causes of lipid accumulation in NASH are the excess of lipids and carbohydrates from diet, increase in de novo lipid synthesis and decrease in lipid oxidation associated with a decrease in hepatic lipid excretion, FXR is becoming one of the most interesting drug targets.

FXR is a bile acid sensor that recognizes specific DNA response elements and binds to them as a heterodimer with retinoid $\mathrm{X}$ receptor. Binding of bile acids to FXR leads to the repression of expression of rate-limiting enzymes in the synthesis of bile acids such as cytochrome P450 (CYP) 7A1 and CYP8B1. FXR inhibits de novo lipid synthesis by inducing repression of hepatic Sterol Regulatory Element Binding Protein 1c (SREBP1c), a transcription factor important for the synthesis of fatty acids and triglycerides. The FXR also inhibits the transcriptional activity of Carbohydrate Response Element Binding Protein (ChREBP), a transcriptional factor implicated in gluconeogenesis and triglyceride synthesis. In addition, FXR interacts with and inhibits directly ChREBP and hepatocyte nuclear factor 4 alpha (HNF4 $\alpha$ ) proteins [23]. HNF4 $\alpha$ is also implicated in the synthesis of bile acids by increasing CYP7A1 and CYP8B1 $[23,90]$.

Fibroblast Growth Factor 21 (FGF21), one of the FXR target genes mainly expressed in the liver, increases fatty acid oxidation, adiponectin secretion and decreases leptin levels. FGF21 also inhibits lipogenesis by repressing SREBP1c and decreases triglyceride and blood glucose levels [91]. Therefore, FGF21 actions have positive effects on plasma lipid levels and hepatic steatosis $[92,93]$.

At the same time, FXR activates expression of hepatic genes involved in lipoprotein clearance from the plasma such as LDL receptor, SR-B1 (i.e., HDL receptor) and also molecules that regulate lipoprotein lipase $[63,94,95]$. Therefore, bile acids and derivatives have been investigated as the treatment for NASH.

Ursodeoxycholic Acid (UDCA) is a secondary hydrophilic bile acid usually made by the intestinal microbiota. UDCA is used to treat primary biliary cirrhosis [96]. Then, in several studies UDCA has been tested to treat NASH and controversial conclusions about the efficacy of the treatment to reduce NASH lesions and to improve clinical parameters have been drawn. Some studies have shown that after at least one year of treatment, UDCA improved hepatic steatosis and enzymes and the high dose of UDCA treatment also improved serum fibrosis markers, glycemia and IR $[97,98]$. On the other hand, a study by Leuschner, et al. [99] did not show any beneficial effect of high-dose of UDCA on overall histology features of NASH. Recently, a long-term study combining UDCA with vitamin $E$ showed improvement in liver function (AST, ALT, $\gamma$-GT) among the 101 patients enrolled. Out of those, 10 patients underwent a biopsy and histology were performed before and after treatment. Five patients did not improve their NAS score ( 0 or- 1 ), one patient had an increased NAS score, and 4 patients showed a decreased of at least -2 points of NAS score. Also, during the study period eighteen $(n=18)$ patients stopped the treatment because of diarrhea, nausea, pruritus, ineffectiveness, or spontaneously $(\mathrm{n}=9)$ and the other $(\mathrm{n}=9)$ because of pregnancy or normalization of biochemical parameters [78]. These results do not seem very conclusive, which is also supported by a few other papers debating on the subject [100-102]. A larger cohort is needed to understand and to better identify the responder and non-responder patient populations. At this point, UDCA is not recommended for the treatment of NAFLD or NASH by the Food and Drug Administration in USA [37].

Nonetheless, bile acid conjugates have recently been tested such as Ursodeoxycholyl lysophosphatidylethanolamide (UDCA-LPE) that has been used on high-fat diet mouse model and showed a a modification in 
fatty acid metabolism, hepatoprotective and anti-inflammatory effects [103-106]. Moreover, it has been shown that UDCA-LPE modulates flawed fatty acid metabolism in mice fed High-Fat Diet (HFD) thus restoring altered lipid profiles and has pronounced anti-inflammatory effects [107]. Further investigations have to be done in patients with NASH.

Obeticholic acid, a synthetic bile acid acting as a ligand of FXR, showed efficacy in animal models [108]. Therefore, a multicenter, double-blind, placebo-controlled (1:1), randomized phase II clinical trial has been conducted by NASH Clinical Research Network in non-cirrhotic and non-alcoholic steatohepatitis (FLINT) [109]. The study showed improvement in histological features of NASH in 50\% of 141 patients. These encouraging results have been balanced by side effects as $33(23 \%)$ of 141 patients in the obeticholic acid developed pruritus compared with nine (6\%) of 142 in the placebo group. Also, another study showed that obeticholic acid treatment had the same results on NAFLD activity score (-1.7 SD 1.8) as vitamin E (-1.9 SD 2.1) and pioglitazone (-0.7 SD 1.8) [79]. Less than $50 \%$ of patients are responders, mainly patients with diabetes, leaving a substantial proportion of patients with NASH without an effective treatment [110].

Singh, et al. [111] performed a Bayesian network metaanalysis combining treatment comparison to assess the efficacy of pharmacological compounds for the treatment of NASH. All studies included in the analysis used biopsy-proven NASH and compared effects of vitamin E, TZDs, pentoxifylline or obeticholic acid to each other or placebo. Interestingly, they showed that depending on the drugs or combination of drugs, improvement of histological features was not the same. Pentoxifylline and Obeticholic acid improved fibrosis, whereas vitamin E, TZDs and Obeticholic acid improved ballooning degeneration. Further investigation using combinations of drugs has to be done to increase efficacy (i.e., every patient with NASH improved) and decrease side effects (i.e., decrease digestive perturbation and pruritus). Another FXR agonist, the newly renamed GS 9674 is currently being evaluated in a phase I study (ClinicalTrials.gov NCT02654002). Hence, bile acid derivatives seem promising for NASH treatments.

\section{Prebiotics, probiotics and "synbiotics" as treatments of NASH}

For more than a decade, microbiota has been in the focus of attention of the scientific community especially when it comes to its role in the development and progression of chronic liver diseases such as NAFLD, cirrhosis and HCC [112-116]. Several studies have suggested that alterations in intestinal microbiota and inflammatory response might play a central role in the development and progression of NASH [117131]. Following this idea, the goal is to modify gut microbiota by using either specific nutrients, or directly by ingesting specific mix of microbes or by using both approaches also known as prebiotics, probiotics or "synbiotics", respectively.

Prebiotic treatments: Prebiotics are defined as a group of nutrients composed mainly of non-digestible carbohydrates (e.g. fibers, fructo-oligosaccharides) that beneficially affect the host by altering the composition and thus the activity of the gut microbiota [132]. Mouse model of NASH treated with Fructo-Oligosaccharides (FOS) showed changes in their gut microbiota and a decrease in n-3 PUFA synthesis modulating hepatic steatosis toward changing in gene expression in the liver [133]. In rats fed HFD, FOS supplementation prevented deleterious effects of HFD such as alterations in lipid profile and hepatic morphologic changes [134]. Also, mice fed HFD supplemented with $6 \%$ hydroxypropyl methylcellulose, usually used as emulsifier, thickening and suspending agent, showed improvement on intestinal permeability, insulin resistance, hepatic lipid accumulation, glucocorticoid-related bile acid recycling, oxidative stress, and weight gain [135]. Because thiazolidinedione treatment leads to weight gain, Alligier, et al. [136] used prebiotic treatment to counteract the side effects of TZDs in animal models. Inulin-type fructan prebiotics decreased adiposity and improved the metabolic response in HFD-fed mice treated with TZDs.

In human clinical trials, FOS has been used to treat NAFLD but did not show efficacy in NASH improvement as observed in animal models. This lack of efficiency in treated patients might be due to power, randomized, controlled clinical trials, involving various centers and the population of different origin, but also to assessing NASH improvement mainly by measuring ALT, a non-specific marker of NASH, and using different doses of prebiotics $[137,138]$. Recently, a double blinded, placebo controlled, parallel group study, adults (BMI $\geq 25 \mathrm{~kg} / \mathrm{m}^{2}$ ) with confirmed NAFLD randomized to either a $16 \mathrm{~g}$ /day prebiotic or isocaloric diet, was conducted. However, the study is still in progress and no results are available yet [139].

Probiotic treatments: A direct approach to modifing intestinal microbiota are probiotics -live microorganisms- which, when administered properly, confer beneficial effects on the host [140]. Therefore using probiotics to modulate gut microbiota and to improve NASH have been considered for a decade [141,142]. Interestingly, studies on mouse models of NASH showed that probiotic VSL\#3 ${ }^{\circledR}$, a mixture of eight probiotics, modulated liver fibrosis but did not decrease steatosis and inflammation in liver [143], whereas in ApoE deficient mice, VSL\#3 ${ }^{\circledR}$ corrected insulin resistance in liver and adipose tissues and protected against development of steatohepatitis [144]. On the other hand, mouse fed high-fat/ high sucrose diet and treated with Lactobacillus paracasei showed attenuation of hepatic steatosis and increased M2-dominant Kupffer cells in a NASH model [145]. In rat models of NASH a specific probiotic inducing butyrate production, Clostridium butyricum (MIYAIRI 588), showed a beneficial effect in the prevention of NAFLD progression [146]. Supplementation on sodium butyrate in mice fed Western diet were also protected from inflammation in the liver and thus from the development of NASH [147].

Despite the controversial results in animal models, clinical trials using probiotics have been recently conducted with promising results. A first pilot study was conducted on 28 patients with histology-proven NAFLD, who were analyzed in a double-blind randomized clinical trial. Patients were randomized to one of the following treatments during 3 months: group I, treated with one tablet per day with 500 million of Lactobacillus bulgaricus and Streptococcus thermophilus and group II, treated with one placebo tablet (120 mg of starch) showed improvement on liver aminotransferases levels in patients with NAFLD but no data are available on liver histology [148]. Another pilot study including patients with NASH assessed by histology was randomized to receive probiotics $(\mathrm{n}=10)$ or usual care $(\mathrm{n}=10)$ during 6 months. The Lepicol ${ }^{\circledR}$ probiotic formula contains Lactobacillus plantarum, Lactobacillus delbrueckii, Lactobacillus acidophilus, Lactobacillus rhamnosus and Bifidobacterium bifidum combined with fiber (Psyllium husks) and inulin. This proof of concept study showed promising results in reducing liver fat and AST level in NASH patients [149]. The same group conducted a study with a larger group of patients ( $n=22$ controls and $n=16$ NASH patients) and looked at gut microbiota. They showed that NASH patients had fecal dysbiosis and changes in microbiota correlate with improvement in hepatic steatosis [150].

Synbiotic treatments: Combining both prebiotics and probiotics approaches (i.e., synbiotics) might further improve the effect of each treatment given alone. Based on this idea, a larger study was conducted by another group including random trials that involved patients with NASH assessed by histology before and after the end of the study. Patients were divided into two groups one of which received Bifidobacterium longum with FOS and lifestyle modification (i.e., diet and exercise) while the other had lifestyle modification alone. The group of patients receiving Bifidobacterium longum with FOS and lifestyle modification had decreased inflammation, serum AST, HOMA-IR, serum endotoxin, hepatic steatosis, and the NASH activity index compared to the lifestyle modification 
group. Importantly, a decrease in BMI was observed in both groups of patients suggesting that pre- and/or probiotics have to be associated with a different therapeutic effect [151]. Recently, a randomized, double-blinded, placebo-controlled clinical trial was conducted as a pilot study on 52 patients with NAFLD diagnosed on the basis of the presence of hepatic steatosis on ultrasound examination, fibrosis score determined by transient elastography, and with a persistently elevated ALT concentration ( $60 \mathrm{U} / \mathrm{L})$ during 6 months before the study. The patients were randomized and the follow-up was conducted at 7, 14, 21 and 28 weeks. Data showed that synbiotic supplementation, in addition to lifestyle modification, has a better outcome compared to lifestyle modification alone for the treatment of NAFLD, at least partially through attenuation of serum inflammatory markers. These effects were seen at the beginning of week 14, and this trend was sustained until the end of the study [152]. The main downsides of this study are that liver histology was not performed, making it difficult to make a conclusion about the improvement of NASH, and uncertainty as to whether these effects will be sustained with longer treatment durations.

Taken together these results underscore the fact that more randomized studies with larger cohorts have to be conducted. Also, more combinations of bacteria need to be tested on a larger number of patients during a longer time period, which will allow to completely changing their gut microbiota. This treatment also has to be associated/combined with other approaches (e.g., control of diet, lifestyle changes) and drug treatments.

\section{Other drugs under evaluation}

The elafibranor, a potent agonist of $\operatorname{PPAR} \alpha / \delta$, recently completed a phase IIb in 276 patients with NASH in Europe and USA [153]. This drug has shown significant activity on the regression of NASH and on markers of liver fibrosis, as well as significant improvement in cardiovascular risk. Elafibranor should start phase III clinical trials in 2016.

C-C chemokine receptors type 2 and 5 (CCR2 and CCR5, respectively) were shown to be implicated in inflammation and fibrosis. Cenicriviroc an antagonist of CCR2 and CCR5, is in phase IIb development in a multicenter study. This study included patients with NASH and fibrosis. The goal of this study is to treat patients with cenicriviroc to improve NASH activity score without worsening fibrosis [154].

Finally, simtuzumab and Apoptosis Signal-regulating Kinase 1 (ASK1) inhibitor (GS 4997), are also being evaluated alone or in combination (NCT02466516). ASK1 is implicated in apoptosis process and inflammation. Using ASK1 inhibitor might decrease and limit inflammation during NASH progression [155].

\section{Next step approaches}

Adiponectin receptor agonists: Adiponectin is a hormone secreted from adipose tissue and binds to adiponectin receptors AdipoR1 and AdipoR2 to activate LKB1-AMPK and PPAR $\alpha$, respectively. Adiponectin binding to AdipoR1 decreases neoglucogenesis, fasting glucose and SREBP1c activation whereas binding to AdipoR2, it increases fatty acid oxidation and energy expenditure. Thus, adiponectin has antidiabetic effects and limits steatosis development [156].

Recently, a synthetic small molecule named AdipoRon has been tested on obese rodent model $\mathrm{db} / \mathrm{db}$ mice. Data showed that $\mathrm{db} / \mathrm{db}$ mice treated orally by AdipoRon have an insulin resistance index and plasma glucose level decreased by acting on white adipose tissue, muscle and liver. In addition, mice fed high fat and treated daily at $30 \mathrm{mg}$ per $\mathrm{kg}$ body weight with AdipoRon showed an increase in longevity. Therefore, AdipoRon could achieve the same outcome much like caloric restriction and exercise. Moreover, AdipoRon showed an anti-inflammatory effect [157].
Taken together, small-molecule AdipoR agonists are very promising candidates for NASH treatment. Further experiments have to be done in rodent models that developed NASH to assess their efficacy.

Honokiol therapy: Honokiol, a major phenolic constituent isolated from Magnolia officinalis extracts, has been reported to have several pharmacological effects, including anti-inflammatory, anti-thrombosis, antioxidant effects and anti-cancerous effects. For few years now honokiol has been shown to have liver protective effects, especially by decreasing fatty liver through the decrease in SREB1c activity and AMPK-LKB1 pathway [158,159]. Therefore, honokiol significantly inhibited SREBP1c maturation and the transcription of lipogenic genes such as Stearoyl-CoA Desaturase-1 (SCD-1) and Fatty Acid Synthases (FAS) in fatty liver [159]. Also, in high-fat diet mouse model of NAFLD, honokiol and magnolol (also a phenolic constituent isolated from Magnolia officinalis) showed a significant decrease in fatty acid accumulation in the liver through the activation of AMPK leading to the inhibition of LXR $\alpha$-SREBP1c pathway [160]. These drugs might be interesting to control fatty liver accumulation but further investigations need to be done, especially regarding efficacy and safety (i.e., assessing side effects) in patients with NASH.

Nicotinamide riboside drug approach: One of fatty acid overload mechanisms in patients with hepatic steatosis and NASH is mitochondrial dysfunction leading to a decrease in fatty acid $\beta$-oxidation and oxidative phosphorylation, decrease in $\mathrm{NADH} / \mathrm{H}^{+}$oxidation into $\mathrm{NAD}^{+}$(i.e., $\mathrm{NAD}^{+}$ repletion) by the mitochondrial respiratory chain complex leading to the leak of electrons and overproduction of Reactive Oxygen Species (ROS) and lipid peroxidation damaging the mitochondria and leading to a vicious circle $[14,19-22,24,25,161]$. Indeed, $\mathrm{NAD}^{+}$is implicated in numerous physiological processes such as caloric restriction, muscle contraction/heart beating, exercise, circadian rhythms, senescence, kidney, and liver functions.

Recently, Gariani, et al. [162] by using existing liver tissue datasets and high-fat/high-sucrose diet in animal models demonstrated that reduction in hepatic mitochondrial content, function and ATP levels associated with $\mathrm{NAD}^{+}$depletion leads to an increase in liver weight, lipid content and lipid peroxidation. Therefore, using a precursor of $\mathrm{NAD}^{+}$biosynthesis (Nicotinamide Riboside) as preventive or therapeutic strategy, the authors demonstrated the prevention or the reversion of the NAFLD toward activating sirtuin-1 and -3 pathway leading to an increase in $\beta$-oxidation, mitochondrial content and activity These data led to an increased use of nicotinamide riboside to boost $\mathrm{NAD}^{+}$biosynthesis to manage the development or progression of NAFLD in clinical trials [163]. In addition, nicotinamide riboside will target and stimulate the mitochondria in the liver to catalyze the excess of free fatty acids, ergo nicotinamide riboside will also increase ROS production, a second hit during the progression of NASH $[14,19,21]$. These might be a limitation for long-term treatment even if the drug is associated with ROS scavenger such as $\alpha$-tocopherol (i.e., tocopheryl acetate or vitamin E). Because nicotinamide riboside also is not tissue-specific, long-term treatment might have systemic consequences and then side effects. Therefore, further investigations have to be done before using nicotinamide riboside in double-blind, randomized clinical trial to assess efficacy, side effects and safety (i.e., toxicity on other organs).

\section{Conclusion}

NASH associated with metabolic syndrome can progress to advanced fibrosis and cirrhosis. Weight loss and lifestyle modification have been shown to improve NASH. Other medications used for weight loss and metabolic syndrome have been evaluated such as metformin and thiazolidinediones. Alternative regimens using ursodeoxycholic acid, statins and probiotics as well as bariatric surgery have been evaluated but have not been recommended as first-line treatment for NASH. Vitamin E for NASH patients without diabetes seems to be promising. Many molecules are in the pipeline of the development for the treatment 
of NASH, the most advanced being the FXR agonists. The lack of effective treatment for NASH suggests the heterogeneity of patients presenting with the NASH phenotype. Indeed, NASH has many underlying causes of genetic (i.e., differences between individuals) to environment (i.e., geography, diets, socio-cultural differences) with similar histological features. Therefore, no single treatment exists. The best treatment strategy for these patients may be to identify their pathogenic target and develop personalized treatment protocols.

But most importantly, the difficulty in diagnosing NASH without biopsy and therefore, the absence of noninvasive biomarkers makes it difficult to enroll patients in large clinical trials limiting the development of the new molecules.

\section{References}

1. Browning JD, Szczepaniak LS, Dobbins R, Nuremberg P, Horton JD, Cohen JC, et al. Prevalence of hepatic steatosis in an urban population in the United States: impact of ethnicity. Hepatology. 2004;40(6):138795.doi: 10.1002/hep.20466.

2. Loomba R,Sanyal AJ. The global NAFLD epidemic. Nat Rev Gastroenterol Hepatol. 2013;10(11):686-90. doi: 10.1038/nrgastro.2013.171.

3. Ong JP, Younossi ZM. Epidemiology and natural history of NAFLD and NASH. Clin Liver Dis. 2007;11(1):1-16, vii.

4. Ramachandran A, Snehalatha C. Rising burden of obesity in Asia. J Obes. 2010;2010. pii: 868573. doi: 10.1155/2010/868573.

5. Arora A, Sharma P. Non-invasive Diagnosis of Fibrosis in Nonalcoholic Fatty Liver Disease. J Clin Exp Hepatol. 2012;2(2):145-55. doi: 10.1016/S0973-6883(12)60103-0.

6. Baffy G, Brunt EM, Caldwell SH. Hepatocellular carcinoma in non-alcoholic fatty liver disease: an emerging menace. J Hepatol. 2012;56(6):1384-91. doi: 10.1016/j.jhep.2011.10.027.

7. Bugianesi E, Leone N, Vanni E, Marchesini G, Brunello F, Carucci P, et al. Expanding the natural history of nonalcoholic steatohepatitis: from cryptogenic cirrhosis to hepatocellular carcinoma. Gastroenterology. 2002;123(1):134-40.

8. Lam DW, LeRoith D. The worldwide diabetes epidemic. Curr Opin Endocrinol Diabetes Obes. 2012;19(2):93-6. doi: 10.1097/ MED.0b013e328350583a.

9. Starley BQ, Calcagno CJ, Harrison SA. Nonalcoholic fatty liver disease and hepatocellular carcinoma: a weighty connection. Hepatology. 2010;51(5):1820-32. doi: 10.1002/hep.23594.

10. Wanless IR, Lentz JS. Fatty liver hepatitis (steatohepatitis) and obesity: an autopsy study with analysis of risk factors. Hepatology. 1990;12(5):1106-10.

11. Zámbó V, Simon-Szabó L, Szelényi P, Kereszturi E, Bánhegyi G, Csala M. Lipotoxicity in the liver. World J Hepatol. 2013;5(10):550-7. doi: 10.4254/wjh.v5.i10.550.

12. Pascale A, Pais R, Ratziu V. An overview of nonalcoholic steatohepatitis: past, present and future directions. J Gastrointestin Liver Dis. 2010;19(4):415-23.

13. Fracanzani AL, Tiraboschi S, Pisano G, Consonni D, Baragetti A, Bertelli $\mathrm{C}$, et al. Progression of carotid vascular damage and cardiovascular events in non-alcoholic fatty liver disease patients compared to the general population during 10 years of follow-up. Atherosclerosis. 2016;246:208-13. doi: 10.1016/j.atherosclerosis.2016.01.016.

14. Basaranoglu M, Basaranoglu G, Sentürk H. From fatty liver to fibrosis: a tale of "second hit". World J Gastroenterol. 2013;19(8):1158-65.

\section{doi: 10.3748/wjg.v19.i8.1158}

15. Bedossa P, FLIP Pathology Consortium. Utility and appropriateness of the fatty liver inhibition of progression (FLIP) algorithm and steatosis, activity, and fibrosis (SAF) score in the evaluation of biopsies of nonalcoholic fatty liver disease. Hepatology. 2014;60(2):565-75. doi: 10.1002/hep. 27173

16. Bedossa P, Poitou C, Veyrie N, Bouillot JL, Basdevant A, Paradis V, et al. Histopathological algorithm and scoring system for evaluation of liver lesions in morbidly obese patients. Hepatology. 2012;56(5):1751-9. doi: 10.1002/hep.25889.

17. Brunt EM, Kleiner DE, Wilson LA, Belt P, Neuschwander-Tetri BA NASH Clinical Research Network (CRN). Nonalcoholic fatty liver disease (NAFLD) activity score and the histopathologic diagnosis in NAFLD: distinct clinicopathologic meanings. Hepatology. 2011;53(3):810-20. doi: 10.1002/hep.24127.

18. Kleiner DE, Brunt EM, Van Natta M, Behling C, Contos MJ, Cummings OW, et al. Design and validation of a histological scoring system for nonalcoholic fatty liver disease. Hepatology. 2005;41(6):1313-21.

19. Day CP, James OF. Steatohepatitis: a tale of two "hits"? Gastroenterology. 1998;114(4):842-5.

20. Pessayre D, Berson A, Fromenty B, Mansouri A. Mitochondria in steatohepatitis. Semin Liver Dis. 2001;21(1):57-69.

21. Takaki A, Kawai D, Yamamoto K. Multiple hits, including oxidative stress, as pathogenesis and treatment target in non-alcoholic steatohepatitis (NASH). Int J Mol Sci. 2013;14(10):20704-28. doi: 10.3390/ijms141020704.

22. Araseki M, Kobayashi H, Hosokawa M, Miyashita K. Lipid peroxidation of a human hepatoma cell line (HepG2) after incorporation of linoleic acid, arachidonic acid, and docosahexaenoic acid. Biosci Biotechnol Biochem. 2005;69(3):483-90.

23. Caron S, Huaman Samanez C, Dehondt H, Ploton M, Briand O, Lien F, et al. Farnesoid $X$ receptor inhibits the transcriptional activity of carbohydrate response element binding protein in human hepatocytes. Mol Cell Biol. 2013;33(11):2202-11. doi: 10.1128/ MCB.01004-12.

24. Chiappini F, Barrier A, Saffroy R, Domart MC, Dagues N, Azoulay $D$, et al. Exploration of global gene expression in human liver steatosis by high-density oligonucleotide microarray. Lab Invest. 2006;86(2):154-65.

25. Powell EE, Cooksley WG, Hanson R, Searle J, Halliday JW, Powell LW. The natural history of nonalcoholic steatohepatitis: a follow-up study of forty-two patients for up to 21 years. Hepatology. 1990;11(1):7480 .

26. Marchesini G, Petta S, Dale Grave R. Diet, weight loss, and liver health in nonalcoholic fatty liver disease: Pathophysiology, evidence, and practice. Hepatology. 2015. doi: 10.1002/hep.28392.

27. Utzschneider KM, Bayer-Carter JL, Arbuckle MD, Tidwell JM, Richards TL, Craft S. Beneficial effect of a weight-stable, low-fat/low-saturated fat/low-glycaemic index diet to reduce liver fat in older subjects. $\mathrm{Br}$ J Nutr. 2013;109(6):1096-104. doi: 10.1017/S0007114512002966.

28. Rosqvist F, Iggman D, Kullberg J, Cedernaes J, Johansson HE, Larsson A, et al. Overfeeding polyunsaturated and saturated fat causes distinct effects on liver and visceral fat accumulation in humans. Diabetes. 2014;63(7):2356-68. doi: 10.2337/db13-1622.

29. Wouters K, van Gorp PJ, Bieghs V, Gijbels MJ, Duimel H, Lütjohann D, et al. Dietary cholesterol, rather than liver steatosis, leads to hepatic 
inflammation in hyperlipidemic mouse models of nonalcoholic steatohepatitis. Hepatology. 2008;48(2):474-86. doi: 10.1002/ hep. 22363 .

30. Review Team, LaBrecque DR, Abbas Z, Anania F, Ferenci P, Khan $A G$, et al. World Gastroenterology Organisation global guidelines: Nonalcoholic fatty liver disease and nonalcoholic steatohepatitis. J Clin Gastroenterol. 2014;48(6):467-73. doi: 10.1097/ MCG.0000000000000116.

31. Huang MA, Greenson JK, Chao C, Anderson L, Peterman D, Jacobson J, et al. One-year intense nutritional counseling results in histological improvement in patients with non-alcoholic steatohepatitis: a pilot study. Am J Gastroenterol. 2005;100(5):1072-1081. doi: 10.1111/j.1572-0241.2005.41334.x.

32. Ueno T, Sugawara H, Sujaku K, Hashimoto O, Tsuji R, Tamaki S, et al. Therapeutic effects of restricted diet and exercise in obese patients with fatty liver. J Hepatol. 1997;27(1):103-107. doi: 9252081.

33. Wu T, Gao X, Chen M, van Dam RM. Long-term effectiveness of diet-plus-exercise interventions vs. diet-only interventions for weight loss: a meta-analysis. Obes Rev. 2009;10(3):313-323. doi: 10.1111/j.1467-789X.2008.00547.x.

34. Nascimbeni F, Pais R, Bellentani S, Day CP, Ratziu V, Loria P, et al. From NAFLD in clinical practice to answers from guidelines. J Hepatol. 2013;59(4):859-871. doi: 10.1016/j.jhep.2013.05.044.

35. Madero M, Arriaga JC, Jalal D, Rivard C, McFann K, Pérez-Méndez 0 , et al. The effect of two energy-restricted diets, a low-fructose diet versus a moderate natural fructose diet, on weight loss and metabolic syndrome parameters: a randomized controlled trial. 2011;60(11):1551-1559. doi: 10.1016/j.metabol.2011.04.001.

36. Chan DC, Watts GF, Gan S, Wong AT, Ooi EM, Barrett PH. Nonalcoholic fatty liver disease as the transducer of hepatic oversecretion of very-low-density lipoprotein-apolipoprotein B-100 in obesity. Arterioscler Thromb Vasc Biol. 2010;30(5):1043-1050. doi: 10.1161/ ATVBAHA.109.202275.

37. Chalasani N, Younossi Z, Lavine J E, Diehl AM, Brunt EM, Cusi K, et al. The diagnosis and management of non-alcoholic fatty liver disease: practice guideline by the American Gastroenterological Association, American Association for the Study of Liver Diseases, and American College of Gastroenterology. Gastroenterology. 2012;142(7):15921609. doi: 10.1053/j.gastro.2012.04.001.

38. Estruch R, Ros E, Salas-Salvado J, Maria-Isabel Covas, Dolores Corella, Fernando Arós, et al. Primary prevention of cardiovascular disease with a Mediterranean diet. N Engl J Med. 2013;368(14):1279-1290. doi: 10.1056/NEJMoa1200303.

39. Papamiltiadous ES, Roberts SK, Nicoll AJ, Marno C. Ryan, Catherine Itsiopoulos, Agus Salim, et al. A randomised controlled trial of a Mediterranean Dietary Intervention for Adults with Non Alcoholic Fatty Liver Disease (MEDINA): study protocol. BMC Gastroenterol. 2016;16(1):14. doi: 10.1186/s12876-016-0426-3.

40. Aller R, Izaola O, De la Fuente B, De Luis Roman DA. Mediterranean Diet Is Associated with Liver Histology in Patients with Non Alcoholic Fatty Liver Disease. Nutr Hosp. 2015;32(n06):2518-2524.

41. Abenavoli L, Milic N, Peta V, Alfieri F, De Lorenzo A, Bellentani S. Alimentary regimen in non-alcoholic fatty liver disease: Mediterranean diet. World J Gastroenterol. 2014;20(45):1683116840. doi: 10.3748/wjg.v20.i45.16831.

42. Nigam P, Bhatt S, Misra A, Chadha Davinder S, Vaidya Meera, Dasgupta Jharna, et al. Effect of a 6-month intervention with cooking oils containing a high concentration of monounsaturated fatty acids (olive and canola oils) compared with control oil in male Asian Indians with nonalcoholic fatty liver disease. Diabetes Technol Ther. 2014;16(4):255-261. doi: 10.1089/dia.2013.0178.

43. Cormick KG, Scorletti E, Bhatia L, Philip C. Calder, Michael J. Griffin, Geraldine F. Clough, et al. Impact of high dose n-3 polyunsaturated fatty acid treatment on measures of microvascular function and vibration perception in non-alcoholic fatty liver disease: results from the randomised WELCOME trial. Diabetologia. 2015;58(8):19161925. doi: 10.1007/s00125-015-3628-2.

44. Scorletti E, Bhatia L, McCormick KG, Geraldine F. Clough, Kathryn Nash, Leanne Hodson, et al. Effects of purified eicosapentaenoic and docosahexaenoic acids in nonalcoholic fatty liver disease: results from the Welcome* study. Hepatology. 2014;60(4):1211-1221. doi: 10.1002/hep.27289.

45. Bhatia L, Scorletti E, Curzen N, Clough GF, Calder PC, Byrne CD. Improvement in non-alcoholic fatty liver disease severity is associated with a reduction in carotid intima-media thickness progression. Atherosclerosis. 2016;246(13-20). doi: 10.1016/j. atherosclerosis.2015.12.028.

46. Barrera F, George J. The role of diet and nutritional intervention for the management of patients with NAFLD. Clin Liver Dis. 2014;18(1):91112. doi: 10.1016/j.cld.2013.09.009.

47. Parker HM, Johnson NA, Burdon CA, Cohn JS, O'Connor HT, George J. Omega-3 supplementation and non-alcoholic fatty liver disease: a systematic review and meta-analysis. J Hepatol. 2012;56(4):944-951. doi: 10.1016/j.jhep.2011.08.018.

48. Pahua-Ramos ME, Garduno-Siciliano L, Dorantes-Alvarez L, German Chamorro-Cevallos, Julieta Herrera-Martínez, Obed Osorio-Esquivel, et al. Reduced-calorie avocado paste attenuates metabolic factors associated with a hypercholesterolemic-high fructose diet in rats. Plant Foods Hum Nutr. 2014;69(1):18-24. doi: 10.1007/s11130-0130395-4.

49. Gupta V, Mah XJ, Garcia MC, Antonypillai C, van der Poorten D. Oily fish, coffee and walnuts: Dietary treatment for nonalcoholic fatty liver disease. World J Gastroenterol. 2015;21(37):10621-10635. doi: 10.3748/wjg.v21.i37.10621.

50. Molloy JW, Calcagno CJ, Williams CD, Jones FJ, Torres DM, Harrison SA. Association of coffee and caffeine consumption with fatty liver disease, nonalcoholic steatohepatitis, and degree of hepatic fibrosis. Hepatology. 2012;55(2):429-436. doi: 10.1002/hep.24731.

51. Sakata R, Nakamura T, Torimura T, Ueno T, Sata M. Green tea with high-density catechins improves liver function and fat infiltration in non-alcoholic fatty liver disease (NAFLD) patients: a double-blind placebo-controlled study. Int J Mol Med. 2013;32(5):989-994. doi: 10.3892/ijmm.2013.1503.

52. Anty R, Marjoux S, Iannelli A, Stéphanie Patouraux, Anne-Sophie Schneck, Stéphanie Bonnafous, et al. Regular coffee but not espresso drinking is protective against fibrosis in a cohort mainly composed of morbidly obese European women with NAFLD undergoing bariatric surgery. J Hepatol. 2012;57(5):1090-1096. doi: 10.1016/j. jhep.2012.07.014.

53. Loftfield E, Freedman ND, Graubard BI, Kristin A. Guertin, Amanda Black, Wen-Yi Huang, et al. Association of Coffee Consumption With Overall and Cause-Specific Mortality in a Large US Prospective Cohort Study. Am J Epidemiol. 2015;182(12):1010-1022. doi: 10.1093/aje/ kwv146.

54. O’Keefe JH, Bhatti SK, Patil HR, DiNicolantonio JJ, Lucan SC, Lavie CJ. 
Effects of habitual coffee consumption on cardiometabolic disease, cardiovascular health, and all-cause mortality. J Am Coll Cardiol. 2013;62(12):1043-1051. doi: 10.1016/j.jacc.2013.06.035.

55. Fabricatore AN. Behavior therapy and cognitive-behavioral therapy of obesity: is there a difference? J Am Diet Assoc. 2007;107(1):92-99. doi: 10.1016/j.jada.2006.10.005.

56. Jensen MD, Ryan DH, Apovian CM, Jamy D, Anthony G. Comuzzie, Frank B. Hu,et al. 2013 AHA/ACC/TOS guideline for the management of overweight and obesity in adults: a report of the American College of Cardiology/American Heart Association Task Force on Practice Guidelines and The Obesity Society. Circulation. 2014;129(25 Suppl 2):102-138. doi: 10.1161/01.cir.0000437739.71477.ee.

57. Keating SE, Hackett DA, George J, Johnson NA. Exercise and nonalcoholic fatty liver disease: a systematic review and meta-analysis. J Hepatol. 2012;57(1):157-166. doi: 10.1016/j.jhep.2012.02.023.

58. Ratziu V, Bellentani S, Cortez-Pinto H, Day C, Marchesini G. A position statement on NAFLD/NASH based on the EASL 2009 special conference. J Hepatol. 2010;53(2):372-384. doi: 10.1016/j. jhep.2010.04.008.

59. Terra X, Auguet T, Guiu-Jurado E, Alba Berlanga, Josep Maria OrellanaGavaldà, Mercè Hernández, et al. Long-term changes in leptin chemerin and ghrelin levels following different bariatric surgery procedures: Roux-en-Y gastric bypass and sleeve gastrectomy. Obes Surg. 2013;23(11):1790-1798. doi: 10.1007/s11695-013-1033-9.

60. American Diabetes A. Standards of medical care in diabetes--2014. Diabetes Care. 2014;37(1):14-80. doi: 10.2337/dc14-S014.

61. Poirier P, Cornier MA, Mazzone T, Stiles S, Cummings S, Klein S, et al. Bariatric surgery and cardiovascular risk factors: a scientific statement from the American Heart Association. Circulation. 2011;123(15):1683-701. doi: 10.1161/CIR.0b013e3182149099.

62. Jerome Dargent. Novel Endoscopic Management of Obesity. Clin Endosc. 2016;49(1):30-36. Doi: 10.5946/ce.2016.49.1.30.

63. Aguilar-Olivos NE, Almeda-Valdes P, Aguilar-Salinas CA, Uribe M, Méndez-Sánchez N. The role of bariatric surgery in the management of nonalcoholic fatty liver disease and metabolic syndrome. Metabolism. 2015. pii: S0026-0495(15)00258-9. Doi: 10.1016/j. metabol.2015.09.004.

64. Sjöström L, Peltonen M, Jacobson P, Sjöström CD, Karason K, Wedel $\mathrm{H}$, et al. Bariatric surgery and long-term cardiovascular events. JAMA. 2012;307(1):56-65. Doi: 10.1001/jama.2011.1914.

65. Hutter MM, Schirmer BD, Jones DB, Ko CY, Cohen ME, Merkow RP, et al. First report from the American College of Surgeons Bariatric Surgery Center Network: laparoscopic sleeve gastrectomy has morbidity and effectiveness positioned between the band and the bypass. Ann Surg. 2011;254(3):410-20; discussion 420-2. Doi: 10.1097/SLA.0b013e31822c9dac.

66. Lassailly G, Caiazzo R, Buob D, Pigeyre M, Verkindt H, Labreuche J et al. Bariatric Surgery Reduces Features of Nonalcoholic Steatohepatitis in Morbidly Obese Patients. Gastroenterology. 2015;149(2):379-88; quiz e15-6. Doi: 10.1053/j.gastro.2015.04.014.

67. Goossens N, Hoshida Y, Song WM, Jung M, Morel P, Nakagawa S, et al. Nonalcoholic Steatohepatitis Is Associated With Increased Mortality in Obese Patients Undergoing Bariatric Surgery. Clin Gastroenterol Hepatol. 2015. pii: S1542-3565(15)01406-8. Doi: 10.1016/j. cgh.2015.10.010.

68. Weingarten TN, Mantilla CB, Swain JM, Kendrick ML, Oberhansley JM, Burcham RJ, et al. Nonalcoholic steatohepatitis in bariatric patients with a diagnosis of obstructive sleep apnea. Obes Facts. 2012;5(4):587-96. Doi: 10.1159/000342677.

69. Rakoski MO1, Singal AG, Rogers MA, Conjeevaram H. Meta-analysis: insulin sensitizers for the treatment of non-alcoholic steatohepatitis. Aliment Pharmacol Ther. 2010;32(10):1211-21. doi: 10.1111/j.13652036.2010.04467.x.

70. Aithal GP, Thomas JA, Kaye PV, Lawson A, Ryder SD, Spendlove I, et al. Randomized, placebo-controlled trial of pioglitazone in nondiabetic subjects with nonalcoholic steatohepatitis. Gastroenterology. 2008;135(4):1176-84. doi: 10.1053/j.gastro.2008.06.047.

71. Belfort R, Harrison SA, Brown K, Darland C, Finch J, Hardies J, et al. A placebo-controlled trial of pioglitazone in subjects with nonalcoholic steatohepatitis. N Engl J Med. 2006;355(22):2297-307. doi: 10.1056/ NEJMoa060326

72. Musso G, Cassader M, Rosina F, Gambino R. Impact of current treatments on liver disease, glucose metabolism and cardiovascular risk in non-alcoholic fatty liver disease (NAFLD): a systematic review and meta-analysis of randomised trials. Diabetologia. 2012;55(4):885-904. Doi: 10.1007/s00125-011-2446-4.

73. Boettcher E, Csako G, Pucino F, Wesley R, Loomba R.Meta-analysis: pioglitazone improves liver histology and fibrosis in patients with non-alcoholic steatohepatitis. Aliment Pharmacol Ther. 2012;35(1):66-75. doi: 10.1111/j.1365-2036.2011.04912.x.

74. Ratziu V, Charlotte F, Bernhardt C, Giral P, Halbron M, Lenaour G, et al. Long-term efficacy of rosiglitazone in nonalcoholic steatohepatitis: results of the fatty liver improvement by rosiglitazone therapy (FLIRT 2) extension trial. Hepatology. 2010;51(2):445-53. Doi: 10.1002/hep. 23270 .

75. Milic S, Mikolasevic I, Krznaric-Zrnic I, Stanic M, Poropat G, Stimac D,et al. Nonalcoholic steatohepatitis: emerging targeted therapies to optimize treatment options. Drug Des Devel Ther. 2015;9:4835-45. Doi: 10.2147/DDDT.S64877.

76. Takahashi Y, Sugimoto K, Inui H, Fukusato T. Current pharmacological therapies for nonalcoholic fatty liver disease/nonalcoholic steatohepatitis. World J Gastroenterol. 2015 ;21(13):3777-85. doi: 10.3748/wjg.v21.i13.3777.

77. Lavine JE. Vitamin E treatment of nonalcoholic steatohepatitis in children: a pilot study. J Pediatr. 2000;136(6):734-8. doi: 10839868.

78. Pietu F, Guillaud O, Walter T, Vallin M, Hervieu V, Scoazec JY, et al. Ursodeoxycholic acid with vitamin $\mathrm{E}$ in patients with nonalcoholic steatohepatitis: long-term results. Clin Res Hepatol Gastroenterol. 2012;36(2):146-55. doi: 10.1016/j.clinre.2011.10.011.

79. Sanyal AJ, Chalasani N, Kowdley KV, McCullough A, Diehl AM, Bass NM, et al. Pioglitazone, vitamin E, or placebo for nonalcoholic steatohepatitis. N Engl J Med. 2010;362(18):1675-1685. doi: 10.1056/NEJMoa090792.

80. Bjelakovic G, Nikolova D, Gluud LL, Simonetti RG, Gluud C. Mortality in randomized trials of antioxidant supplements for primary and secondary prevention: systematic review and meta-analysis. JAMA. 2007;297(8):842-57. doi: 10.1001/jama.297.8.842.

81. Zein CO, Yerian LM, Gogate P, Lopez R, Kirwan JP, Feldstein AE, et al. Pentoxifylline improves nonalcoholic steatohepatitis: a randomized placebo-controlled trial. Hepatology. 2011;54(5):1610-1619. doi: 10.1002/hep.24544.

82. Du J, Ma YY, Yu CH, Li YM. Effects of pentoxifylline on nonalcoholic fatty liver disease: a meta-analysis. World J Gastroenterol. 2014;20(2):569-577. doi: 10.3748/wjg.v20.i2.569. 
83. Nelson A, Torres DM, Morgan AE, Fincke C, Harrison SA. A pilot study using simvastatin in the treatment of nonalcoholic steatohepatitis: A randomized placebo-controlled trial. J Clin Gastroenterol. 2009;43(10):990-994. doi: 10.1097/MCG.0b013e31819c392e.

84. Kargiotis K, Katsiki N, Athyros VG, Giouleme O, Patsiaoura K, Katsiki $\mathrm{E}$, et al. Effect of rosuvastatin on non-alcoholic steatohepatitis in patients with metabolic syndrome and hypercholesterolaemia: a preliminary report. Curr Vasc Pharmacol. 2014;12(3):505-511. doi: 24805248.

85. Laufs U, Scharnagl H, Marz W. Statin intolerance. Curr Opin Lipidol. 2015;26(6):492-501. doi: 10.1097/MOL.0000000000000236.

86. Loomba R, Sirlin CB, Ang B, Bettencourt R, Jain R, Salotti J, et al. Ezetimibe for the treatment of nonalcoholic steatohepatitis: assessment by novel magnetic resonance imaging and magnetic resonance elastography in a randomized trial (MOZART trial). Hepatology. 2015;61(4):1239-1250. doi: 10.1002/hep.27647.

87. Takeshita $Y$, Takamura T, Honda M, Kita Y, Zen $Y$, Kato K, et al. The effects of ezetimibe on non-alcoholic fatty liver disease and glucose metabolism: a randomised controlled trial. Diabetologia. 2014;57(5):878-890. doi: 10.1007/s00125-013-3149-9.

88. Park H, Shima T, Yamaguchi K, et al. Efficacy of long-term ezetimibe therapy in patients with nonalcoholic fatty liver disease. J Gastroenterol. 2011;46(1):101-107. doi: 10.1007/s00535-0100291-8.

89. Enjoji M, Machida K, Kohjima M, Kato M, Kotoh K, Matsunaga K, et al NPC1L1 inhibitor ezetimibe is a reliable therapeutic agent for nonobese patients with nonalcoholic fatty liver disease. Lipids Health Dis. 2010;9(29. doi: 10.1186/1476-511X-9-29.

90. Abrahamsson A, Gustafsson U, Ellis E, Nilsson LM, Sahlin S, Björkhem I, et al. Feedback regulation of bile acid synthesis in human liver: importance of HNF-4alpha for regulation of CYP7A1. Biochem Biophys Res Commun. 2005;330(2):395-399. doi: 10.1016/j. bbrc.2005.02.170.

91. Nakamura MT, Yudell BE, Loor JJ. Regulation of energy metabolism by long-chain fatty acids. Prog Lipid Res. 2014;53:124-144. doi: 10.1016/j.plipres.2013.12.001.

92. Markan KR, Potthoff MJ. Metabolic fibroblast growth factors (FGFs): Mediators of energy homeostasis. Semin Cell Dev Biol. 2015. doi: 10.1016/j.semcdb.2015.09.021.

93. Kim KH, Lee MS. FGF21 as a mediator of adaptive responses to stress and metabolic benefits of anti-diabetic drugs. J Endocrinol. 2015;226(1):R1-16. doi: 10.1530/JOE-15-0160.

94. Aguilar-Olivos NE, Carrillo-Córdova D, Oria-Hernández J, SánchezValle V, Ponciano-Rodríguez G, et al. The nuclear receptor FXR, but not LXR, up-regulates bile acid transporter expression in nonalcoholic fatty liver disease. Ann Hepatol. 2015;14(4):487-493. doi: 26019035.

95. Sanyal AJ. Use of farnesoid $\mathrm{X}$ receptor agonists to treat nonalcoholic fatty liver disease. Dig Dis. 2015;33(3):426-432. doi: 10.1159/000371698.

96. Zhu GQ, Shi KQ, Huang S, Huang GQ, Lin YQ, Zhou ZR, et al. Network meta-analysis of randomized controlled trials: efficacy and safety of UDCA-based therapies in primary biliary cirrhosis. Medicine (Baltimore). 2015;94(11):e609. doi: 10.1097/ MD.0000000000000609.

97. Laurin J, Lindor KD, Crippin JS, Gossard A, Gores GJ, Ludwig J, et al. Ursodeoxycholic acid or clofibrate in the treatment of non-alcohol- induced steatohepatitis: a pilot study. Hepatology. 1996;23(6):14641467. doi: 10.1002/hep.510230624.

98. Ratziu V, de Ledinghen V, Oberti F, Mathurin P, Wartelle-Bladou C, Renou C, et al. A randomized controlled trial of high-dose ursodesoxycholic acid for nonalcoholic steatohepatitis. J Hepatol. 2011;54(5):1011-1019. doi: 10.1016/j.jhep.2010.08.030.

99. Leuschner UF, Lindenthal B, Herrmann G, Arnold JC, Rössle M, Cordes $\mathrm{HJ}$, et al. High-dose ursodeoxycholic acid therapy for nonalcoholic steatohepatitis: a double-blind, randomized, placebo-controlled trial. Hepatology. 2010;52(2):472-479. doi: 10.1002/hep.23727.

100. Liechti F, Dufour JF. Treatment of NASH with ursodeoxycholic acid: cons. Clin Res Hepatol Gastroenterol. 2012;36 Suppl 1: S46-52. doi: 10.1016/S2210-7401(12)70021-9.

101. Ratziu V. Treatment of NASH with ursodeoxycholic acid: pro. Clin Res Hepatol Gastroenterol. 2012;36 Suppl 1: S41-45. doi: 10.1016/ S2210-7401(12)70020-7.

102. Vajro P, Paolella G, Pierri L, D'Aniello R. Treatment of NASH with ursodeoxycholic acid: pros and cons. More information in children. Clin Res Hepatol Gastroenterol. 2013;37(3):e93-94. doi: 10.1016/j. clinre.2013.02.012.

103. Chamulitrat W, Liebisch G, Xu W, et al. Ursodeoxycholyl lysophosphatidylethanolamide inhibits lipoapoptosis by shifting fatty acid pools toward monosaturated and polyunsaturated fatty acids in mouse hepatocytes. Mol Pharmacol. 2013;84(5):696-709. doi: 10.1124/mol.113.088039.

104. Chamulitrat W, Zhang W, Xu W, Pathil A, Setchell K, Stremmel W. Hepatoprotectant ursodeoxycholyl lysophosphatidylethanolamide increasing phosphatidylcholine levels as a potential therapy of acute liver injury. Front Physiol. 2012;3:24. doi: 10.3389/ fphys.2012.00024.

105. Pathil A, Mueller J, Warth A, Chamulitrat W, Stremmel W. Ursodeoxycholyl lysophosphatidylethanolamide improves steatosis and inflammation in murine models of nonalcoholic fatty liver disease. Hepatology. 2012;55(5):1369-1378. doi: 10.1002/ hep.25531.

106. Chamulitrat W, Burhenne J, Rehlen T, Pathil A, Stremmel W. Bile salt-phospholipid conjugate ursodeoxycholyl lysophosphatidylethanolamide as a hepatoprotective agent. Hepatology. 2009;50(1):143-154. doi: 10.1002/hep.22955.

107. Pathil A, Liebisch G, Okun JG, Chamulitrat W, Schmitz G, Stremmel W. Ursodeoxycholyl Lysophosphatidylethanolamide modifies aberrant lipid profiles in NAFLD. Eur J Clin Invest. 2015;45(9):925-931. doi: 10.1111/eci.12486.

108. Kunne C, Acco A, Duijst S, de Waart DR, Paulusma CC, Gaemers I, et al. FXR-dependent reduction of hepatic steatosis in a bile salt deficient mouse model. Biochim Biophys Acta. 2014;1842(5):739-746. doi: 10.1016/j.bbadis.2014.02.004.

109. Neuschwander-Tetri BA, Loomba R, Sanyal AJ, Lavine JE, Van Natta ML, Abdelmalek MF, et al. Farnesoid X nuclear receptor ligand obeticholic acid for non-cirrhotic, non-alcoholic steatohepatitis (FLINT): a multicentre, randomised, placebo-controlled trial. Lancet. 2015;385(9972):956-965. doi: 10.1016/S0140-6736(14)61933-4.

110. Musso G, Cassader M, Gambino R. Trials of obeticholic acid for nonalcoholic steatohepatitis. Lancet. 2015;386(9988):27. doi: 10.1016/ S0140-6736(15)61198-9.

111. Singh S, Khera R, Allen AM, Murad MH, Loomba R. Comparative effectiveness of pharmacological interventions for nonalcoholic 
steatohepatitis: A systematic review and network meta-analysis. Hepatology. 2015;62(5):1417-1432. doi: 10.1002/hep.27999.

112. Son G, Kremer M, Hines IN. Contribution of gut bacteria to liver pathobiology. Gastroenterol Res Pract. 2010; 2010. doi: $10.1155 / 2010 / 453563$.

113. Henao-Mejia J, Elinav E, Thaiss CA, Flavell RA. The intestinal microbiota in chronic liver disease. Adv Immunol. 2013;117:73-97. doi: 10.1016/B978-0-12-410524-9.00003-7.

114. Lade A, Noon LA, Friedman SL. Contributions of metabolic dysregulation and inflammation to nonalcoholic steatohepatitis, hepatic fibrosis, and cancer. Curr Opin Oncol. 2014;26(1):100-107. doi: $10.1097 /$ CCO.0000000000000042.

115. De Minicis S, Rychlicki C, Agostinelli L, Saccomanno S, Candelaresi C, Trozzi L, et al. Dysbiosis contributes to fibrogenesis in the course of chronic liver injury in mice. Hepatology. 2014;59(5):1738-1749. doi: 10.1002/hep.26695.

116. Boursier J, Mueller O, Barret M, Machado M, Fizanne L, AraujoPerez F, et al. The severity of nonalcoholic fatty liver disease is associated with gut dysbiosis and shift in the metabolic function of the gut microbiota. Hepatology. 2016;63(3):764-775. doi: 10.1002/ hep.28356.

117. Dumas ME, Barton RH, Toye A, Cloarec O, Blancher C, Rothwell A, et al. Metabolic profiling reveals a contribution of gut microbiota to fatty liver phenotype in insulin-resistant mice. Proc Natl Acad Sci USA. 2006;103(33):12511-12516. doi: 10.1073/pnas.0601056103.

118. Abu-Shanab A, Quigley EM. The role of the gut microbiota in nonalcoholic fatty liver disease. Nat Rev Gastroenterol Hepatol. 2010;7(12):691-701. doi: 10.1038/nrgastro.2010.172.

119. Spencer MD, Hamp TJ, Reid RW, Fischer LM, Zeisel SH, Fodor AA Association between composition of the human gastrointestinal microbiome and development of fatty liver with choline deficiency. Gastroenterology. 2011;140(3): 976-986. doi: 10.1053/j. gastro.2010.11.049.

120. Henao-Mejia J, Elinav E, Jin C, Hao L, Mehal WZ, Strowig T, et al Inflammasome-mediated dysbiosis regulates progression of NAFLD and obesity. Nature. 2012;482(7384):179-185. doi: 10.1038/ nature10809.

121. Wood NJ. Microbiota: Dysbiosis driven by inflammasome deficiency exacerbates hepatic steatosis and governs rate of NAFLD progression. Nat Rev Gastroenterol Hepatol. 2012;9(3):123. doi: 10.1038/nrgastro.2012.21

122. Compare D, Coccoli P, Rocco A, Nardone OM, De Maria S, Cartenì M, et al. Gut--liver axis: the impact of gut microbiota on non alcoholic fatty liver disease. Nutr Metab Cardiovasc Dis. 2012;22(6):471-476. doi: 10.1016/j.numecd.2012.02.007.

123. Machado MV, Cortez-Pinto H. Gut microbiota and nonalcoholic fatty liver disease. Ann Hepatol. 2012;11(4):440-449.

124. Zhu L, Baker SS, Gill C, Liu W, Alkhouri R, Baker RD, et al Characterization of gut microbiomes in nonalcoholic steatohepatitis (NASH) patients: a connection between endogenous alcohol and NASH. Hepatology. 2013;57(2):601-609. doi: 10.1002/hep.26093.

125. Alisi A, Ceccarelli S, Panera N, Nobili V. Causative role of gut microbiota in non-alcoholic fatty liver disease pathogenesis. Front Cell Infect Microbiol. 2012;2:132. doi: 10.3389/fcimb.2012.00132.

126. Le Roy T, Llopis M, Lepage P, Bruneau A, Rabot S, Bevilacqua C, Martin $\mathrm{P}$, et al. Intestinal microbiota determines development of non-alcoholic fatty liver disease in mice. Gut. 2013;62(12):17871794. doi: 10.1136/gutjnl-2012-303816.

127. Moschen AR, Kaser S, Tilg H. Non-alcoholic steatohepatitis: a microbiota-driven disease. Trends Endocrinol Metab. 2013;24(11):537-545. doi: 10.1016/j.tem.2013.05.009.

128. Aron-Wisnewsky J, Gaborit B, Dutour A, Clement K. Gut microbiota and non-alcoholic fatty liver disease: new insights. Clin Microbiol Infect. 2013;19(4):338-348. doi: 10.1111/1469-0691.12140.

129. Mouzaki M, Comelli EM, Arendt BM, Bonengel J, Fung SK, Fischer SE, et al. Intestinal microbiota in patients with nonalcoholic fatty liver disease. Hepatology. 2013;58(1):120-127. doi: 10.1002/hep.26319.

130. Sanyal AJ. An integrated view of liver injury and disease progression in nonalcoholic steatohepatitis. Hepatol Int. 2013;7 Suppl 2: 800805. doi: $10.1007 / \mathrm{s} 12072-013-9479-3$.

131. Imajo K, Yoneda M, Ogawa Y, Wada K, Nakajima A. Microbiota and nonalcoholic steatohepatitis. Semin Immunopathol. 2014;36(1):115 132. doi: $10.1007 / \mathrm{s} 00281-013-0404-6$.

132. Parnell JA, Raman M, Rioux KP, Reimer RA. The potential role of prebiotic fibre for treatment and management of non-alcoholic fatty liver disease and associated obesity and insulin resistance. Liver Int. 2012;32(5) 701-711. doi: 10.1111/j.1478-3231.2011.02730.x.

133. Pachikian BD, Essaghir A, Demoulin JB, Catry E, Neyrinck AM, Dewulf EM, et al. Prebiotic approach alleviates hepatic steatosis: implication of fatty acid oxidative and cholesterol synthesis pathways. Mol Nutr Food Res. 2013;57(2):347-359. doi: 10.1002/mnfr.201200364.

134. Correia-Sa I, de-Sousa-Lopes H, Martins MJ, Azevedo I, Moura E, Vieira-Coelho MA. Effects of raftilose on serum biochemistry and liver morphology in rats fed with normal or high-fat diet. Mol Nutr Food Res. 2013;57(8):1468-1472. doi: 10.1002/mnfr.201200693.

135. Kim H, Bartley GE, Young SA, Seo KH, Yokoyama W. Altered hepatic gene expression profiles associated with improved fatty liver, insulin resistance, and intestinal permeability after hydroxypropyl methylcellulose (HPMC) supplementation in diet-induced obese mice. J Agric Food Chem. 2013;61(26):6404-6411. doi: 10.1021/ jf400545w.

136. Alligier M, Dewulf EM, Salazar N, Mairal A, Neyrinck AM, Cani PD, et al. Positive interaction between prebiotics and thiazolidinedione treatment on adiposity in diet-induced obese mice. Obesity (Silver Spring). 2014;22(7):1653-1661. doi: 10.1002/oby.20733.

137. Tarantino G, Finelli C. Systematic review on intervention with prebiotics/probiotics in patients with obesity-related nonalcoholic fatty liver disease. Future Microbiol. 2015;10(5):889-902. doi: $10.2217 / \mathrm{fmb} .15 .13$

138. Buss C, Valle-Tovo C, Miozzo S, Alves de Mattos A. Probiotics and synbiotics may improve liver aminotransferases levels in nonalcoholic fatty liver disease patients. Ann Hepatol. 2014;13(5):482488. doi: 25152979 .

139. Lambert JE, Parnell JA, Eksteen B Raman M, Bomhof MR, Rioux KP, et al. Gut microbiota manipulation with prebiotics in patients with non-alcoholic fatty liver disease: a randomized controlled trial protocol. BMC Gastroenterol. 2015;15:169. doi: 10.1186/s12876015-0400-5

140. Hill C, Guarner F, Reid G, Gibson GR, Merenstein DJ, Pot B, et al. Expert consensus document. The International Scientific Association for Probiotics and Prebiotics consensus statement on the scope and appropriate use of the term probiotic. Nat Rev Gastroenterol Hepatol. 2014;11(8):506-514. doi: 10.1038/nrgastro.2014.66. 
141. Nardone G, Rocco A. Probiotics: a potential target for the prevention and treatment of steatohepatitis. J Clin Gastroenterol. 2004;38(6 Suppl): S121-122.

142. Medina J, Fernandez-Salazar LI, Garcia-Buey L, Moreno-Otero R. Approach to the pathogenesis and treatment of nonalcoholic steatohepatitis. Diabetes Care. 2004;27(8):2057-2066.

143. Velayudham A, Dolganiuc A, Ellis M, Petrasek J, Kodys K, Mandrekar P, et al. VSL\#3 probiotic treatment attenuates fibrosis without changes in steatohepatitis in a diet-induced nonalcoholic steatohepatitis model in mice. Hepatology. 2009;49(3):989-997. doi: 10.1002/ hep.22711.

144. Mencarelli A, Cipriani S, Renga B, et al. VSL\#3 resets insulin signaling and protects against NASH and atherosclerosis in a model of genetic dyslipidemia and intestinal inflammation. PLoS One. 2012;7(9):e45425. doi: 10.1371/journal.pone.0045425.

145. Sohn W, Jun DW, Lee KN, Lee HL, Lee OY, Choi HS, et al. Lactobacillus paracasei Induces M2-Dominant Kupffer Cell Polarization in a Mouse Model of Nonalcoholic Steatohepatitis. Dig Dis Sci. 2015;60(11):3340-3350. doi: 10.1007/s10620-015-3770-1.

146. Endo H, Niioka M, Kobayashi N, Tanaka M, Watanabe T. Butyrateproducing probiotics reduce nonalcoholic fatty liver disease progression in rats: new insight into the probiotics for the gutliver axis. PLoS One. 2013;8(5):e63388. doi: 10.1371/journal. pone. 0063388 .

147. Jin CJ, Sellmann C, Engstler AJ, Ziegenhardt D, Bergheim I. Supplementation of sodium butyrate protects mice from the development of non-alcoholic steatohepatitis (NASH). Br J Nutr. 2015;114(11):1745-1755. doi: 10.1017/S0007114515003621.

148. Aller R, De Luis DA, Izaola O, Conde R, Gonzalez Sagrado M, Primo D, et al. Effect of a probiotic on liver aminotransferases in nonalcoholic fatty liver disease patients: a double blind randomized clinical trial. Eur Rev Med Pharmacol Sci. 2011;15(9):1090-1095.

149. Wong VW, Won GL, Chim AM, Chu WC, Yeung DK, Li KC, et al Treatment of nonalcoholic steatohepatitis with probiotics. A proofof-concept study. Ann Hepatol. 2013;12(2):256-262.

150. Wong VW, Tse CH, Lam TT, Wong GL, Chim AM, Chu WC, et al Molecular characterization of the fecal microbiota in patients with nonalcoholic steatohepatitis--a longitudinal study. PLoS One. 2013;8(4):e62885. doi: 10.1371/journal.pone.0062885.

151. Malaguarnera M, Vacante M, Antic T, Giordano M, Chisari $\mathrm{G}$, Acquaviva $\mathrm{R}$, et al. Bifidobacterium longum with fructooligosaccharides in patients with non alcoholic steatohepatitis. Dig Dis Sci. 2012;57(2):545-53. doi: 10.1007/s10620-011-1887-4.

152. Eslamparast T, Poustchi H, Zamani F, Sharafkhah M, Malekzadeh $\mathrm{R}$, Hekmatdoost A. Synbiotic supplementation in nonalcoholic fatty liver disease: a randomized, double-blind, placebo-controlled pilot study. Am J Clin Nutr. 2014;99(3):535-42. doi: 10.3945/ ajcn.113.068890.

153. Ratziu V, Harrison S, Francque S, Bedossa P, Lehert P, Serfaty LS, et al. Elafibranor, an Agonist of the Peroxisome Proliferator-activated Receptor-alpha and -delta, Induces Resolution of Nonalcoholic Steatohepatitis Without Fibrosis Worsening. Gastroenterology. 2016. doi: 10.1053/j.gastro.2016.01.038.

154. Friedman S, Sanyal A, Goodman Z, Lefebvre E, Gottwald M, Fischer L, et al. Efficacy and safety study of cenicriviroc for the treatment of non-alcoholic steatohepatitis in adult subjects with liver fibrosis: Contemp Clin Trials. 2016;47:356-365. doi: 10.1016/j. cct.2016.02.012.

155. Brenner C, Galluzzi L, Kepp O, Kroemer G. Decoding cell death signals in liver inflammation. J Hepatol. 2013;59(3):583-94. doi: 10.1016/j. jhep.2013.03.033.

156. Okada-Iwabu M, Iwabu M, Ueki K, Yamauchi T, Kadowaki T. Perspective of Small-Molecule AdipoR Agonist for Type 2 Diabetes and Short Life in Obesity. Diabetes Metab J. 2015;39(5):363-72. doi: 10.4093/dmj.2015.39.5.363.

157. Okada-Iwabu M, Yamauchi T, Iwabu M, Honma T, Hamagami $\mathrm{K}$, Matsuda $\mathrm{K}$, et al. A small-molecule AdipoR agonist for type 2 diabetes and short life in obesity. Nature. 2013;503(7477):493-499. doi: $10.1038 /$ nature12656.

158. Nagalingam A, Arbiser JL, Bonner MY, Saxena NK, Sharma D. Honokiol activates AMP-activated protein kinase in breast cancer cells via an LKB1-dependent pathway and inhibits breast carcinogenesis. Breast Cancer Res. 2012; 14(1):R35. doi: 10.1186/bcr3128.

159. Seo MS, Kim JH, Kim HJ, Chang KC, Park SW. Honokiol activates the LKB1-AMPK signaling pathway and attenuates the lipid accumulation in hepatocytes. Toxicol Appl Pharmacol. 2015;284(2):113-124. doi: 10.1016/j.taap.2015.02.020.

160. Lee JH, Jung JY, Jang EJ, Jegal KH, Moon SY, Ku SK, et al. Combination of honokiol and magnolol inhibits hepatic steatosis through AMPKSREBP-1 c pathway. Exp Biol Med (Maywood). 2015;240(4):508518. doi: $10.1177 / 1535370214547123$.

161. Day CP, Yeaman SJ. The biochemistry of alcohol-induced fatty liver. Biochim Biophys Acta. 1994;1215(1-2):33-48.

162. Gariani K, Menzies KJ, Ryu D, Wegner CJ, Wang X, Ropelle ER, et al. Eliciting the mitochondrial unfolded protein response by nicotinamide adenine dinucleotide repletion reverses fatty liver disease in mice. Hepatology. 2016;63(4):1190-204. doi: 10.1002/ hep. 28245.

163. Gual P, Postic C. Therapeutic potential of nicotinamide adenine dinucleotide for nonalcoholic fatty liver disease. Hepatology. 2016;63(4):1074-7. doi: 10.1002/hep.28383. 